\title{
FRICTIONAL RESISTANCE OF ACTIVE AND PASSIVE AESTHETIC SELF-LIGATING BRACKETS WITH DIFFERENT ORTHODONTIC WIRE SIZES
}

\author{
Yasser M. Emam¹, Sherif S. Morcos², Mohammed A. Nadim³, Abbadi A. ElKady ${ }^{4}$
}

The purpose of this study was to investigate the effect of passive and active self-ligation of aesthetic brackets on the static and kinetic friction with different wire sizes. Two types of ceramic brackets were used; Empower Clear (active self-ligating bracket (ASLB)) and Damon Clear 2 (passive self-ligating bracket (PSLB)). They were coupled with $0.017 \times 0.025$-in and 0.019 $x$ 0.025-in stainless-steel (SS) wires. A universal testing machine was used to pull the brackets along the distal end of the archwire. The test was performed at $5 \mathrm{~mm} / \mathrm{min}$ crosshead speed over a distance of $8 \mathrm{~mm}$ to measure the static friction (SF) and the Kinetic friction (KF) under dry conditions. The results showed the PSLB's to have significantly lower SF and KF with both wire sizes.

\section{INTRODUCTION}

Ceramic brackets have higher frictional properties than those of metal brackets $^{1-4}$, however they are experiencing great interest these days due to the increased esthetic needs of the orthodontic patients. Self- ligating systems may be of great benefit to reduce the friction associated with sliding mechanics, especially when using ceramic brackets, as they show less frictional resistance than those of conventional brackets. ${ }^{5-7}$, The ligation force has a direct effect on friction ${ }^{8}$ among other factors like the archwire size, angulation and material together with the bracket width and the bracket slot dimensions in addition to the inter bracket distance?

Reducing the frictional forces can allow us to measure retraction forces more accurately, since frictional forces can consume up to 50 or 60 per cent of the retraction forces exerted on a tooth. ${ }^{10,11}$ Therefore Low friction is important to achieve tooth movement within the biological limits during the working stage of treatment and space closure and thus reduces the hyalinization phase which reduces the treatment duration as well as the root resorption.

Two types of friction should be overcome in order for tooth movement to occur: (1) Static friction to initiate the tooth movement and (2) kinetic friction to maintain the tooth movement. They are affected by normal force of ligation, the coefficient of friction between a certain bracket and wire materials, the binding between the bracket and the wire as well as other factors.

Two types of self-ligating brackets exist nowadays those with a clip or a spring that presses the wire into the bracket slot (active self-ligating brackets) and those with a slide, door or a clip that engages the wire passively in the bracket slot (passive self-ligating brackets). In this study a passive and an active ceramic self-ligating brackets are examined with two

1- Post graduate student, Orthodontics department, Faculty of Dentistry, Suez Canal University

2- Assistant Professor of Orthodontics, Faculty of Dentistry, Suez Canal University

3- Assistant Professor of Orthodontics, Faculty of Dentistry, Suez Canal University

4- Professor and Head of Orthodontics department, Faculty of Dentistry, Suez Canal University 
sizes of stainless steel archwires to compare the effect of the ligation mode as well as the size of the wire on their frictional properties.

\section{MATERIALS AND METHODOLOGY}

Two types of ceramic maxillary right canine self-ligating brackets were used, thirty Damon Clear 2 PSLB's (Ormco, Orange, CA, USA) (Figure 1) and thirty Empower Clear ASLB's (American Orthodontics, Sheboygan, Wisconsin, USA) (Figure 2). Each type was divided into two halves where fifteen brackets were coupled with a $0.019 \times 0.025$-in SS archwire and the other fifteen brackets coupled with a $0.017 \times 0.025$-in SS archwire.

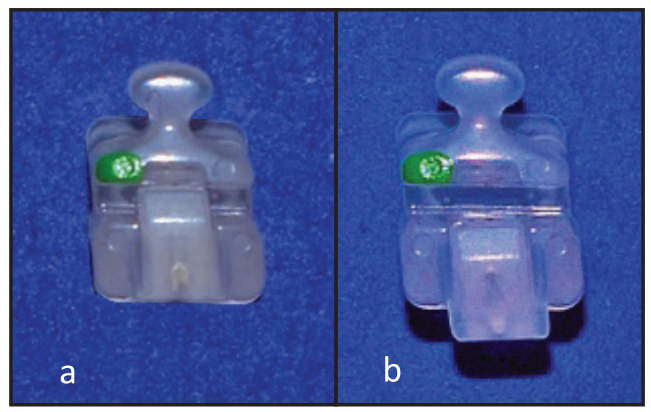

Fig (1): a) Damon Clear 2 bracket in closed mode. b) Open mode.

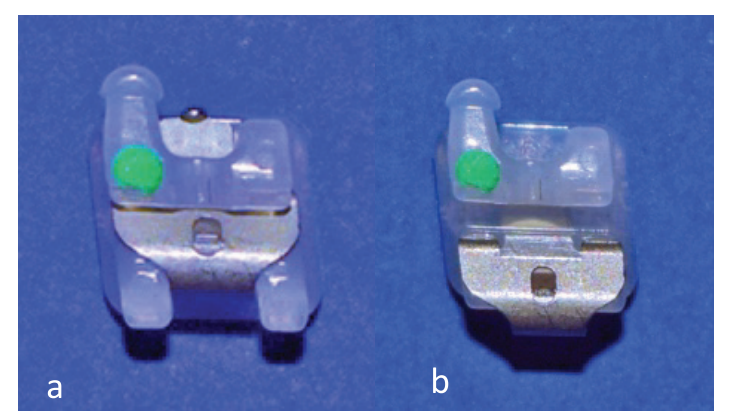

Fig (2): a) Empower Clear bracket in closed mode, b) in opened mode

All the brackets were made of polycrystalline alumina with a slot dimension of $0.022 \times 0.028$-in. The PSLB's had a sliding door that does not grip the wire inside the slot but holds it passively and had a $7^{\circ}$ torque and a $5^{\circ}$ angulation. The ASLB's grip the wire inside the bracket slot by means of an interactive clip that actively engages archwire sizes of 0.017 x 0.025 -in and larger in a 0.022 slot. These brackets have a $0^{\circ}$ torque and an $8^{\circ}$ angulation. These brackets were bonded on a metal block with a curved surface using epoxy resin. To overcome the prescription differences between the brackets a special trough like structure was custom made with the internal dimensions the as those of the metal blocks. Five blocks were aligned in this structure and the brackets were aligned using two edge wise brackets one on each side and a 0.021 x 0.025-in SS wire jig, (figure 3).

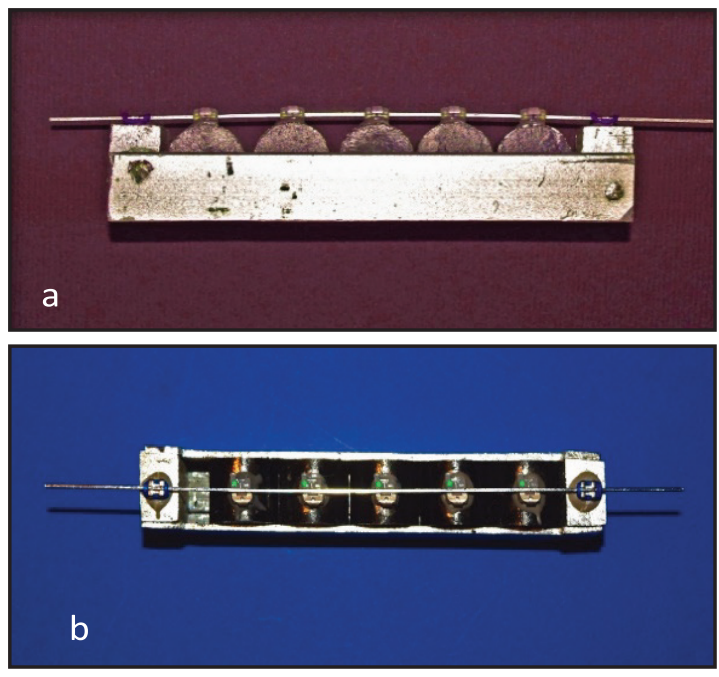

Fig (3): a) Alignment of brackets on the blocks using a $0.021 \times 0.025$-in SS wire, b) mesiodistal alignment of brackets

A custom designed attachment composed of two parts the an upper part holding the block/ bracket assembly and a lower part holding the wire segment. A universal testing machine (Instron Model 3345, Norwood, MA, USA) was used to slide the brackets along the distal end of the archwires which were cut into two halves at the mid line (Figure 4). The test was performed under dry conditions at a crosshead speed of 5 $\mathrm{mm} / \mathrm{min}$ over a distance of $8 \mathrm{~mm}$ that resembles the mean mesiodistal premolar width. ${ }^{4,}{ }^{12}$ Each bracket and wire segment were used only once for testing. 


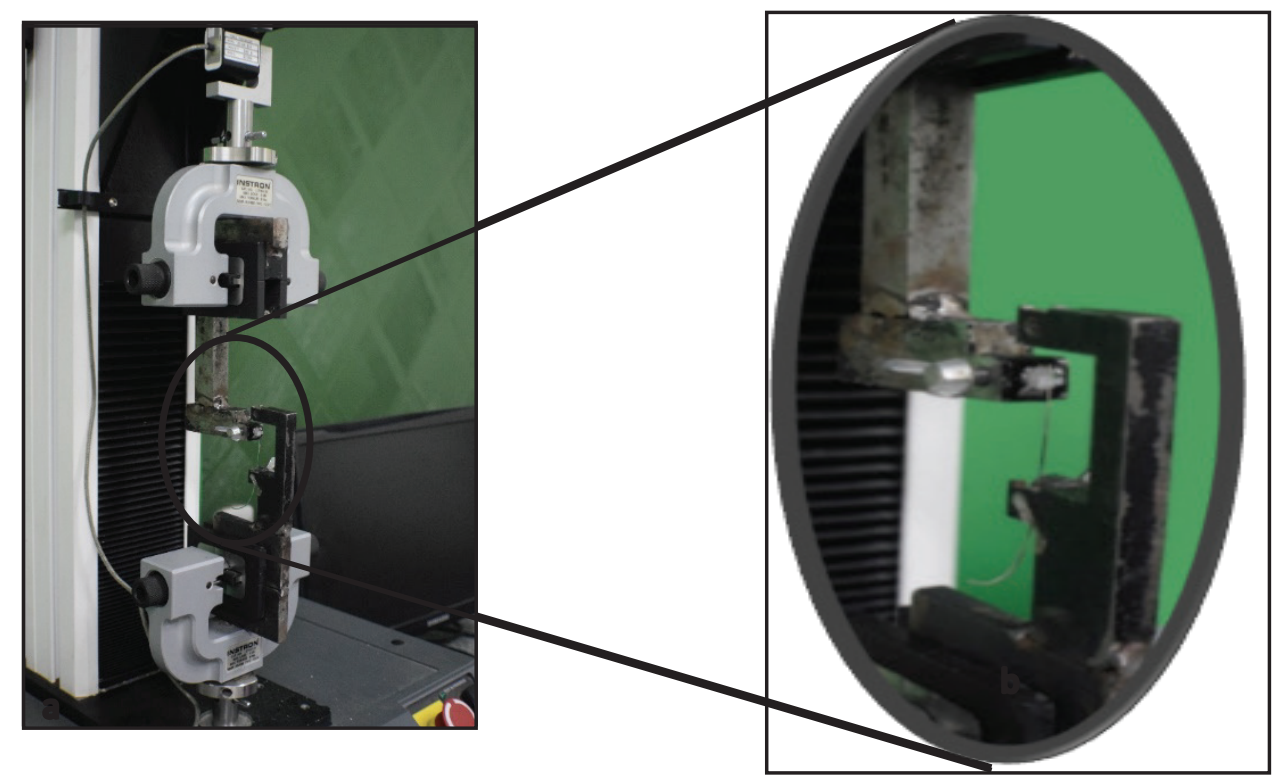

Fig (4): a) The Instron machine holding the attachments with the bracket and wire in place, b) a larger picture of the attachment holding the bracket and wire

The data were collected and processed using the Bluehill software designed for use with the Instron machines. The SF was represented as the highest force recorded. The KF was represented as the mean of eight readings recorded for each test as the bracket slid along 8 $\mathrm{mm}$ of the wire segment (a reading every $1 \mathrm{~mm}$ ) which sums as 120 readings for each bracket/ wire combination with a total of 480 readings through the experiment and all the readings were recorded in Newton $(\mathrm{N})$. Student's t-test was used to determine the significance of the effect of the two types of brackets and the two wire sizes on SF and KF. Two way analysis of variance (ANOVA) was used to detect the effect of the wire size and the ligation mode and their interaction on SF and KF and as a confirmatory for the t-test. The tests were performed using the computer program Statistical Package for Social Science (SPSS, Inc., Chicago, IL, USA) version 17.0.

\section{RESULTS}

\section{Effect of the two types of brackets on static friction:}

Table (1) and the histogram (Figure 5) showed a significant increase in the static friction for the ASLB than the PSLB regardless of the size of the archwire used for testing.

Table (1): Comparison between the mean static frictions of the two bracket types with both wire sizes

\begin{tabular}{|c|c|c|c|c|c|}
\hline \multirow{3}{*}{ Wire Size } & \multicolumn{4}{|c|}{ Brackets } & \multirow{3}{*}{ P-value } \\
\hline & \multicolumn{2}{|c|}{ Damon Clear (PSLB) } & \multicolumn{2}{|c|}{ Empower Clear (ASLB) } & \\
\hline & Mean & \pm SD & Mean & \pm SD & \\
\hline $17 \times 25$ mil & .182 & .111 & 1.373 & .671 & $<0.05$ \\
\hline 19x25 mil & .722 & .418 & 1.843 & .797 & $<0.05$ \\
\hline
\end{tabular}

SD: standard deviation

significance $<0.05$ Test used: Student's t-test 


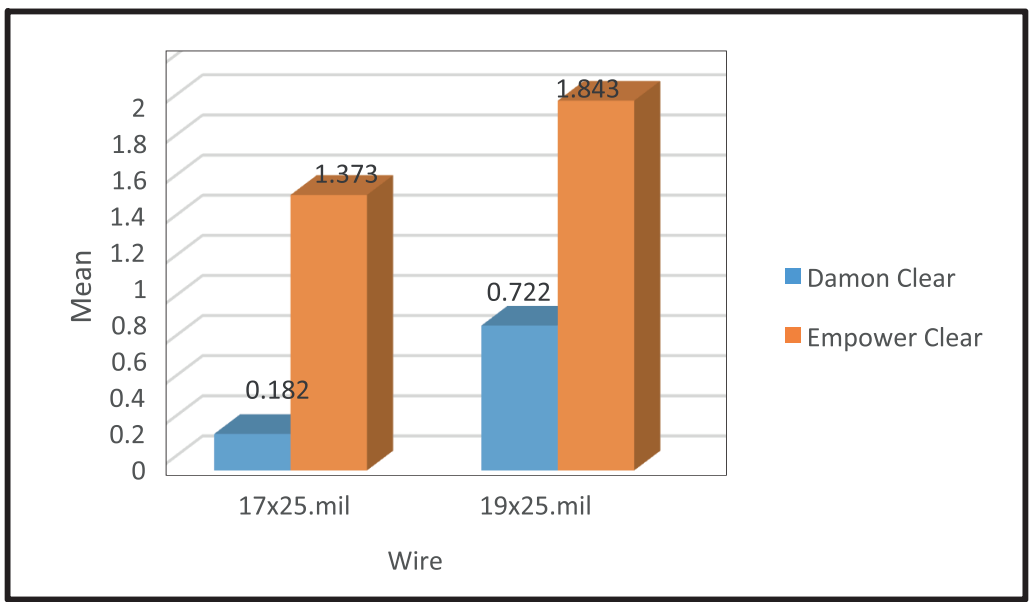

Fig (5): Histogram comparing the mean static frictions of the two brackets with both wire sizes

\section{II.Effect of the wire size on the static}

\section{friction:}

Table (2) and the histogram in (figure 6) showed a significant increase in the static friction for the ASLB when the wire size increased from $0.017 \times 0.025$-in to $0.019 \times$ 0.025 -in. However, the increase in SF with the wire size was not statistically significant for the PSLB.

Table (2): Comparison between the mean static frictions of the two wire sizes with both brackets

\begin{tabular}{|l|c|c|c|c|c|}
\hline \multirow{2}{*}{ Brackets } & \multicolumn{4}{|c|}{ Wire } & \multirow{2}{*}{} \\
\cline { 2 - 5 } & \multicolumn{2}{|c|}{$17 \times 25 . m i l$} & \multicolumn{2}{|c|}{ 19x25.mil } & \multirow{2}{*}{ P-value } \\
\cline { 2 - 5 } & Mean & \pm SD & Mean & \pm SD & \\
\hline Damon Clear (PSLB) & .182 & .111 & .722 & .418 & $<0.05$ \\
\hline Empower Clear (ASLB) & 1.373 & .671 & 1.843 & .797 & $>0.05$ \\
\hline
\end{tabular}

SD: standard deviation significance $<0.05$ Test used: Student's t-test

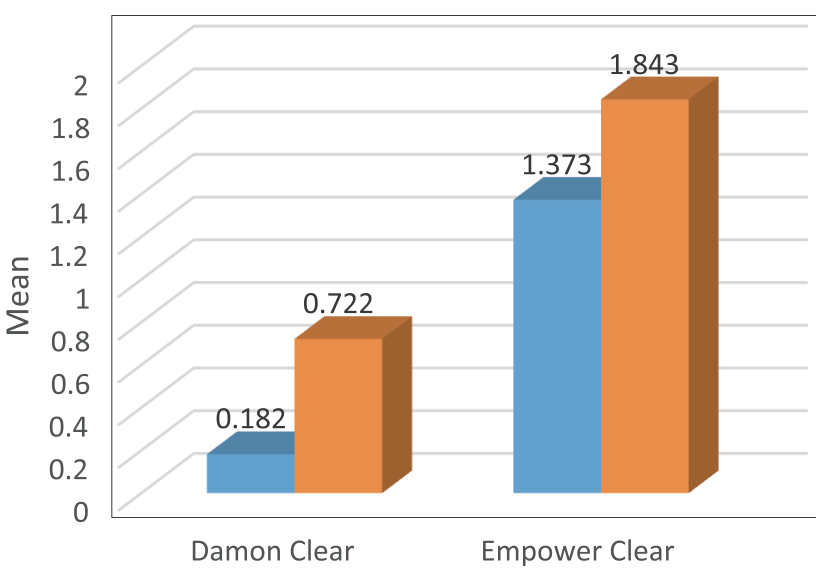

Fig (6): Histogram comparing the mean static frictions of the two wire sizes with both brackets 
The two way ANOVA in table (3) confirmed the results of the t-test where increasing the wire size from $0.017 \times 0.025$-in to $0.019 \times 0.025$-in increased the SF significantly regardless of the type of bracket used. It also showed that changing the ligation type from the passive to the active self-ligation had a highly significant effect on increasing the static friction regardless of the size of the wire. However, changing the wire size from $0.017 \times 0.025$-in to $0.019 \times 0.025$-in had an equal effect on increasing the static friction on both bracket types with no significant difference between them.

Table (3): Effect of brackets and wire sizes on static friction

\begin{tabular}{|c|c|c|}
\hline Source & F-value & P-value \\
\hline Wire & 12.020 & $<0.05$ \\
\hline Brackets & 63.140 & $<0.05$ \\
\hline Wire * Brackets & .059 & $>0.05$ \\
\hline
\end{tabular}

Test used: Two-way ANOVA significance $<0.05$

III.Effect of the two types of brackets on the kinetic friction:

As can be noticed from table (4) as well as the histogram (Figure 7), the results were similar for the KF to that of the SF, where the ASLB showed a significant increase in the KF than that of the PSLB with the $0.017 \times 0.025$-in wire as well as with the $0.019 \times 0.025$-in wire.

Table (4): Comparison between the mean kinetic frictions of the two bracket types with both wire sizes

\begin{tabular}{|c|c|c|c|c|c|}
\hline \multirow{2}{*}{ Wire } & \multicolumn{4}{|c|}{ Brackets } & \multirow{2}{*}{} \\
\cline { 2 - 5 } & \multicolumn{2}{|c|}{ Damon Clear (PSLB) } & \multicolumn{2}{|c|}{ Empower Clear (ASLB) } & \multirow{2}{*}{ P-value } \\
\cline { 2 - 5 } & Mean & \pm SD & Mean & \pm SD & \\
\hline 17x25.mil & .075 & .041 & .926 & .567 & $<0.05$ \\
\hline $19 \times 25 . m i l$ & .396 & .241 & 1.314 & .767 & $<0.05$ \\
\hline
\end{tabular}

SD: standard deviation significance $<0.05$

Test used: Student's t-test 


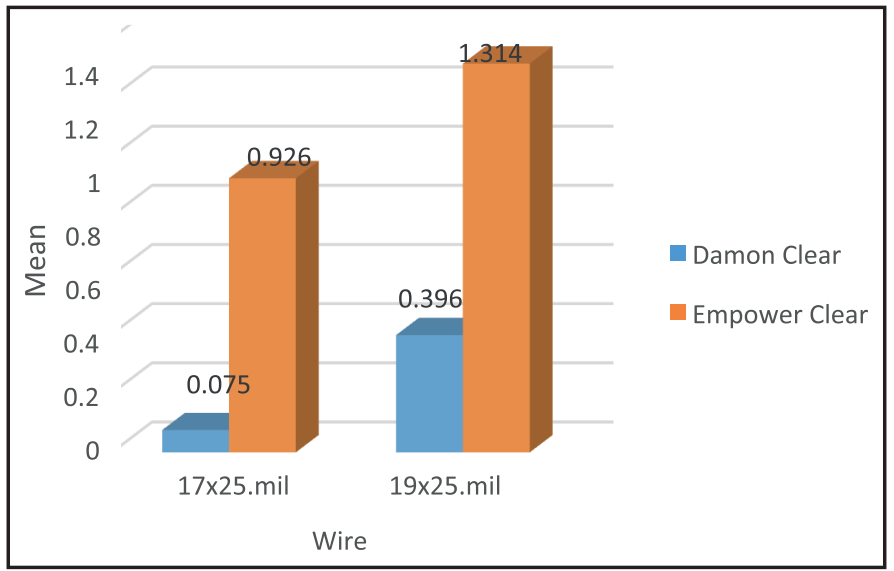

Fig (7): Histogram comparing the mean kinetic frictions of the two brackets with both wire sizes IV. Effect of the wire size on kinetic friction:

The results in table (5) and the histogram in (Figure 8) showed that increasing the wire size from $0.017 \times 0.025$-in to $0.019 \times 0.025$ in had statistically significant effect on ncreasing the kinetic friction for the passive bracket. However the increasing the wire size showed a statistically insignificant increase in the kinetic friction for the active bracket.

Table (5): Comparison between the mean kinetic frictions of the two wire sizes with both brackets

\begin{tabular}{|c|c|c|c|c|c|}
\hline \multirow{2}{*}{ Brackets } & \multicolumn{4}{|c|}{ Wire } & \multirow{2}{*}{ P-value } \\
\cline { 2 - 5 } & \multicolumn{2}{|c|}{$17 \times 25 . m i l$} & \multicolumn{2}{|c|}{$19 \times 25 . m i l$} & \multirow{2}{*}{} \\
\cline { 2 - 5 } & Mean & \pm SD & Mean & \pm SD & \\
\hline Damon Clear (PSLB) & .075 & .041 & .396 & .241 & $<0.05$ \\
\hline Empower Clear (ASLB) & .926 & .567 & 1.314 & .767 & $>0.05$ \\
\hline
\end{tabular}

SD: standard deviation significance $<0.05$

Test used: Student's t-test

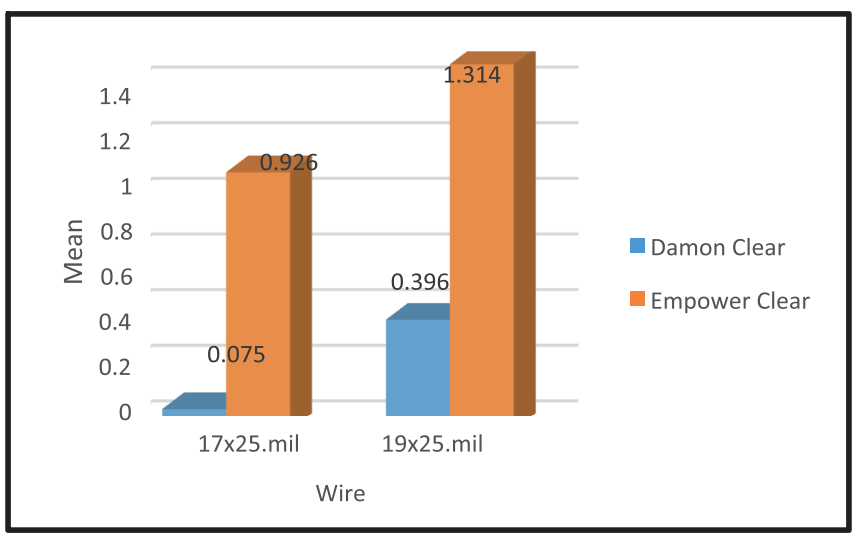

Fig (8): Histogram comparing the mean kinetic frictions of the two wire sizes with both brackets 
The two way ANOVA from (table 6) for the kinetic friction also confirmed the results of the t-test as it also showed that there was a significant increase in the KF when increasing the wire size from $0.017 \times 0.025$ to $0.019 \times 0.025$-in regardless of the type of ligation used. It also showed that the KF increased significantly when changing from passive to active ligation regardless of the size of the wire used. However as found with the static friction, changing the wire size had an equal effect on increasing the kinetic friction with the same amount in both bracket types with no significant difference between them.

Table (6): Effect of brackets and wire sizes on kinetic friction

\begin{tabular}{|c|c|c|}
\hline Source & F-value & P-value \\
\hline Wires & 7.768 & $<0.05$ \\
\hline Brackets & 48.438 & $<0.05$ \\
\hline Wire * Brackets & .068 & $>0.05$ \\
\hline
\end{tabular}

Test used: Two-way ANOVA $\quad$ significance $<0.05$

\section{DISCUSSION}

The results of the current study showed that there was a significant effect for the mode of ligation on the static and kinetic frictions, where the active ligation had a significant effect over the passive ligation in increasing the static as well as the kinetic friction with both wire sizes.

In like manner, the results of Muguruma et $\mathrm{al}^{13}$ were in accordance with those of the present study except in one situation in which the brackets were combined with the $0.019 \times 0.025$-in SS wire with the application of a $30^{\circ}$ torque. This can be attributed to the high degree of the applied torque and the high stiffness of the wire. In contrast to the results found in the current study, were those of Reznikov et $\mathrm{al}^{10}$ who found no significant differences between the PSLB's and ASLB's in the SF and KF when tested at zero deflection. However, as the deflection increased the active self-ligating brackets showed lower static friction compared to the passive self-ligating brackets. They attributed this to the stiffness of the ligature mechanism of the passive self-ligating brackets (door or clip) than that of the active ones (spring).

Other studies did not totally agree with the results of the present study like those of Thorstenson and Kusy ${ }^{12}$ who found that passive self-ligating brackets had lower frictional resistance than the active self-ligating brackets when coupled with larger wires. However, when it comes to smaller wire sizes like 0.014-in there were no significant differences between the two types of brackets and this was dependent on the amount of clearance between the wire and the bracket slot. Also, Tecco et al ${ }^{14-}$ ${ }^{16}$ reported in three different studies using the same experimental setup, that the passive selfligating brackets demonstrated lower frictional resistance with round wires. However, they reported lower frictional resistance for the active than the 
passive self-ligating brackets with the rectangular wires in their first study ${ }^{14}$, but found no significant difference between the active and passive types with rectangular wires in the two other studies ${ }^{15}$, ${ }^{16}$. This may be due the difference in the method of bracket alignment between those studies and that of the present study. Voudouris et $a 11^{7}$ also reported no significant difference between a ceramic active self-ligating bracket and a semi-aesthetic passive self-ligating bracket, however they both showed lower frictional resistance than the metal active self-ligating bracket used in their study. This shows that ceramic self-ligating brackets could have comparable frictional properties to that of metal correspondents.

In respect to the wire size and its effect on the SF and KF, the results of the present study were contradicted by those of Kahlon et $\mathrm{al}^{18}$. They found no measurable static friction for the passive self-ligating brackets when combined with both the $0.016 \times 0.022$-in and the $0.018 \times 0.022$-in SS wires they used in their study. On the other hand, the static friction was affected by the size of the wire for the active brackets. This may be attributed to the difference in the bracket material used in the present study (ceramic) and those used in theirs (metal) as it was reported in other studies $^{1955}$. Brauchli et $\mathrm{al}^{20}$ found also that increasing the wire size had an effect on increasing the static friction of the active selfligating brackets while that of the passive brackets remained unaffected. This may be due to the difference in the experimental setup as a moment was applied in their study. Opposing to the results of the present study came also those of Reicheneder et al ${ }^{21}$ who found the $0.018 \mathrm{x}$ 0.025 -in wire to produce less static friction than the $0.017 \times 0.025$-in and the $0.019 \times 0.025$-in. This may be due to summing the results of all the self-ligating brackets together as a hall.
Contradictive to the results of the present study, Oliver et $\mathrm{al}^{22}$ reported that the passive brackets were not affected by the increase in wire dimensions. However, the kinetic friction of the active and interactive selfligating brackets increased when the wire size increased from $0.017 \times 0.022$-in to $0.017 \mathrm{x}$ 0.025 -in and $0.019 \times 0.025$-in. but they were not affected by the increase in wire dimensions from $0.017 \times 0.025$-in to $0.019 \times 0.025$-in. Therefore, they suggested that the frictional forces are only affected by the depth of the wire but not the height. This also may be due to the difference in the experimental setup as the typodont tooth was allowed to rotate and tip during retraction.

\section{CONCLUSION}

Based on the results of this study the following conclusions could be drawn:

A) If lower static and kinetic frictions were required during sliding of ceramic brackets along the arch wire as in cases of canine retraction or en masse retraction, it is preferred to use passive self-ligating brackets.

B) The frictional forces will not be affected if the wire size increased from $0.017 \times 0.025$ to $0.019 \times 0.025$-in when performing canine retraction using active self-ligating ceramic brackets. However, when using a passive selfligating ceramic bracket a larger wire size will produce higher frictional forces during retraction.

\section{REFERENCES}

1. Cacciafesta V, Sfondrini MF, Scribante A, Klersy C, Auricchio F. Evaluation of friction of conventional and metal-insert ceramic brackets in various bracket-archwire combinations. Am J Orthod Dentofacial Orthop. 2003;124(4):403-409.

2. Nishio C, da Motta AF, Elias CN, Mucha $\mathrm{JN}$. In vitro evaluation of frictional forces between archwires and ceramic brackets. Am J 
Orthod Dentofacial Orthop. 2004;125(1):56-64.

3. Doshi UH, Bhad-Patil WA. Static frictional force and surface roughness of various bracket and wire combinations. Am J Orthod Dentofacial Orthop. 2011;139(1):74-79.

4. Fidalgo TK, Pithon MM, Maciel JV, Bolognese AM. Friction between different wire bracket combinations in artificial saliva--an in vitro evaluation. J Appl Oral Sci. 2011;19(1):57-62. 5. Williams CL, Khalaf K. Frictional Resistance of Three Types of Ceramic Brackets. J Oral Maxillofac Res. 2013;4(4):e3.

6. Jakob SR, Matheus D, Jimenez-Pellegrin MC, Turssi CP, Amaral FLB. Comparative study of friction between metallic and conventional interactive self-ligating brackets in different alignment conditions. Dental Press J Orthod. 2014;19(3):82-89.

7. Fathimani M, Melenka GW, Romanyk DL, Toogood RW, Heo G, Carey JP, Major PW. Development of a standardized testing system for orthodontic sliding mechanics. Prog Orthod. 2015;16:14-25.

8. Smith DV, Rossouw P, Watson P. Quantified Simulation of Canine Retraction: Evaluation of Frictional Resistance. Semin Orthod. 2003;9(4):262-280.

9. Henao SP, Kusy RP. Evaluation of the frictional resistance of conventional and self-ligating bracket designs using standardized archwires and dental typodonts. Angle Orthod. 2004;74(2):202-211.

10. Reznikov N, Har-Zion G, Barkana I, Abed Y, Redlich M. Measurement of friction forces between stainless steel wires and "reduced- friction" self-ligating brackets. Am J Orthod Dentofacial Orthop. 2010;138(3):330-338.

11. Huang TH, Luk HS, Hsu YC, Kao CT. An in vitro comparison of the frictional forces between archwires and self-ligating brackets of passive and active types. The Eur J Orthod. $2011 ; 34(5): 625-632$.

12. Thorstenson GA, Kusy RP. Effect of archwire size and material on the resistance to sliding of self-ligating brackets with second-order angulation in the dry state. Am J Orthod Dentofacial Orthop. 2002;122(3):295-305.

13. Muguruma $T$, Iijima $M$, Brantley WA, Ahluwalia KS, Kohda N, Mizoguchi I. Effects of third-order torque on frictional force of selfligating brackets. Angle Orthod. 2014;84(6): 1054-1061.

14. Tecco S, Festa F, Caputi S, Traini T, Di Iorio D, D'Attilio M. Friction of conventional and self-ligating brackets using a 10 bracket model. Angle Orthod. 2005;75(6):1041-1045.

15. Tecco S, Di Iorio D, Cordasco G, Verrocchi I, Festa F. An in vitro investigation of the influence of self-ligating brackets, low friction ligatures, and archwire on frictional resistance. Eur J Orthod. 2007;29(4):390-397.

16. Tecco S, Di Iorio D, Nucera R, Di Bisceglie B, Cordasco G, Festa F. Evaluation of the friction of self-ligating and conventional bracket systems. Eur J Dent. 2011;5(3):310-317.

17. Voudouris JC, Schismenos C, Lackovic K, Kuftinec MM. Self-ligation esthetic brackets with low frictional resistance. Angle Orthod. 2010;80(1):188-194. 
18. Kahlon S, Rinchuse D, Robison JM, Close JM. In-vitro evaluation of frictional resistance with 5 ligation methods and Gianelly-type working wires. Am J Orthod Dentofacial Orthop. 2010;138(1):67-71.

19. Karim Soltani M, Golfeshan F, Alizadeh Y, Mehrzad J. Resistance to Sliding in Clear and Metallic Damon 3 and Conventional Edgewise Brackets: an In vitro Study. J Dent (Shiraz). 2015;16(1 Suppl):15-20.

20. Brauchli LM, Senn C, Wichelhaus A. Active and passive self-ligation-a myth? Angle Orthod. 2011;81(2):312-318.

21. Reicheneder CA, Gedrange T, Berrisch S, Proff P, Baumert U, Faltermeier A, Muessig D. Conventionally ligated versus self-ligating metal brackets-a comparative study. Eur J Orthod. 2008;30(6):654-660.

22. Oliver CL, Daskalogiannakis J, Tompson BD. Archwire depth is a significant parameter in the frictional resistance of active and interactive, but not passive, self-ligating brackets. Angle Orthod. 2011;81(6):1036-1044. 

